Revista 2020

\title{
Aspectos éticos del docente en la enseñanza del derecho*
}

\author{
Edwin Secergio Trujillo Florián ${ }^{a}$ Miryam Edith Barón Colmenares ${ }^{b}$
}

\begin{abstract}
Resumen: El proceso de reflexión permite establecer la pregunta ¿cuáles son los componentes éticos que pueden guiar y complementar la función del docente en derecho? La enseñanza del derecho consiste en impartir conceptos teóricos de la dogmática, sus escuelas y su evolución, sin embargo, el proceso queda incompleto porque no existe un vínculo entre el derecho, la ética y la política conforme a lo planteado por Kennedy (2007) y un enfoque de las capacidades conforme a los presupuestos de Sen (1996). El presente artículo tiene como objetivo describir aspectos de justicia social en la enseñanza del derecho y el enfoque de las capacidades, además busca hacer una reflexión de la labor del docente de derecho y su ética. Se proponen algunas líneas de pensamiento filosófico y bioético mediante la investigación documental interpretativa; el proceso reflexivo se establece por medio de la información obtenida y analizada en textos y artículos de revistas indexadas a partir del análisis crítico del discurso. Destaca como conclusión principal la importancia de constituir unos criterios que permitan complementar la labor de la enseñanza tradicional del derecho como la ética de la justicia social para los menos favorecidos, la ayuda humanitaria, el vínculo emocional docente-estudiante y los nuevos derechos.
\end{abstract}

Palabras clave: justicia social; ética; capacidades; bioética; compasión.

Recibido: 10 de junio de 2020. Aceptado: 19 de junio de 2020

Disponible en línea: 22 de octubre de 2020.

Cómo citar: Trujillo Florián, E. S. y Barón Colmenares, M. E. (2020). Aspectos éticos del docente en la enseñanza del derecho. Academia y Virtualidad, 13(2), 145-158. https://doi.org/10.18359/ravi.4899

* Artículo de reflexión.

a Doctor en Bioética. Profesor Asistente Universidad Militar Nueva Granada, Cajicá, Colombia. Correo electrónico: edwin.trujillo@unimilitar.edu.co ORCID: https://orcid.org/0000-0003-2203-7704

b Magíster en docencia. Profesora Universidad Militar Nueva Granada, Cajicá, Colombia. Correo electrónico: miryam.baron@unimilitar.edu.co ORCID: http://orcid.org/0000-0002-8454-697X 


\section{Professor ethical aspects in law teaching}

Abstract: The reflection process allows us to establish the question: what are the ethical components that can guide and complement the role of the law teacher? Teaching law involves the theoretical concepts of dogmatics, its schools and its evolution, however, the process remains incomplete because there is no link between law, ethics and politics as suggested by Kennedy (2007) neither a capability-focused approach according to Sen's (1996) assumptions. The objective of this article is to describe aspects of social justice in the teaching of law and the capacities approach, it also seeks to reflect on the work of the law professors and their ethics. Some lines of philosophical and bioethical thought are proposed through interpretative documental research; the reflective process is established through the information obtained and analyzed in texts and articles of indexed journals from the critical analysis of discourse. A main conclusion that stands out is the importance of establishing criteria that allow complementing the work of the traditional teaching of law, such as the ethics of social justice for the less favored, humanitarian aid, the teacher-student emotional bond and the new laws.

Keywords: social justice; ethics; capabilities; bioethics; compassion

\section{Aspectos éticos do docente no ensino do direito}

Resumo: O processo de reflexão permite estabelecer a seguinte pergunta: quais são os componentes éticos que podem guiar e complementar a função do docente em direito? $\mathrm{O}$ ensino do direito consiste em apresentar conceitos teóricos da dogmática, suas escolas e sua evolução, no entanto, o processo fica incompleto porque não existe um vínculo entre o direito, a ética e a política conforme o proposto por Kennedy (2007) e uma abordagem das capacidades conforme os pressupostos de Sen (1996). O presente artigo tem como objetivo descrever aspectos de justiça social no ensino do direito e o enfoque das capacidades, além disso, procura fazer uma reflexão sobre o trabalho do docente de direito e sua ética. Propõem-se algumas linhas de pensamento filosófico e bioético mediante a pesquisa documental interpretativa; o processo reflexivo estabelece-se por meio da informação obtida e analisada em textos e artigos de revistas indexadas a partir da análise crítica do discurso. Destaca como conclusão principal a importância de constituir alguns critérios que permitam complementar o trabalho do ensino tradicional do direito como a ética da justiça social para os menos favorecidos, a ajuda humanitária, o vínculo emocional docente-estudante e os novos direitos.

Palavras-chave: justiça social; ética; capacidades; bioética; compaixão 


\section{Introducción}

El presente artículo describe los principales componentes éticos que pueden guiar y complementar la función del docente en derecho. El principal problema ha sido que la enseñanza del derecho ha consistido exclusivamente en la impartición de los conceptos teóricos de la dogmática, sus escuelas y su evolución, además, el modelo de abogado presentado por los medios de comunicación y los docentes tradicionales genera falsas premisas ${ }^{1}$. La justificación de este trabajo se da porque en la experiencia de los autores se ha evidenciado que este proceso queda incompleto ya que no existe un vínculo entre el derecho, la ética y la política conforme a lo planteado por Kennedy (2007) en su deseo de politizar la enseñanza del derecho, además, debe existir un enfoque en las capacidades conforme a los presupuestos de Sen (1996).

En primer término, se analiza la enseñanza del derecho como una manifestación de la justicia social que debe estar inmersa en los planes curriculares y en el ejercicio de la docencia, para ello se tuvieron en cuenta los criterios de Connell (1997) en el desarrollo de los principios que deben regir los currículos en las aulas; de Benjamin (2001) para establecer la importancia de la memoria del docente como posibilidad de garantizar la justicia hacia el estudiante quien se encuentra en una posición desfavorable y de necesidad; y la bioética global como puente que garantiza que entre la teoría (o dogmática) del derecho deba existir un vínculo con lo humano para hacer efectiva la sostenibilidad del ser humano.

En segundo término, se describen los criterios básicos de una ética en la labor docente como una ayuda humanitaria para la población estudiantil

1 El imaginario social del modelo de abogado que presentan algunos medios de comunicación corresponde a un profesional que no tiene los escrúpulos para asumir las causas que se le presenten sin analizar las consecuencias. Es un abogado que no le interesa la ética, ni los principios morales, sino solamente ganar el caso y figurar mediáticamente a fin de obtener mejores réditos. En el caso del docente universitario, popularmente se considera que es un docente que no se involucra con sus estudiantes, solo le interesa dictar su clase sin importar el contexto social e integral del estudiante y excluye a los estudiantes que muestran falencias que no son de su agrado. de escasos recursos. En este sentido, se evidenciaron unas cifras de la población general de los estudiantes de derecho que permiten señalar que en su mayoría estos pertenecen a los estratos 1,2 y 3 y que conforme a estas cifras los docentes juegan un papel importante en la reducción de las desigualdades económicas y sociales de sus estudiantes. Para el desarrollo de este objetivo se sugirió que el docente debe recurrir al enfoque de las capacidades de Amartya Sen, a los fundamentos éticos de la ayuda humanitaria de su labor explicados por Xabier Etxeberria, en especial la compasión y por último debe tener en cuenta la aplicación analógica de la relación médico-paciente tratada por la bioética para que la interacción docente-estudiante sea más humana.

Se discutieron los resultados en tanto que la investigación es exclusivamente documental interpretativa y el proceso reflexivo se estableció por medio de la información obtenida y analizada en textos y artículos de revistas indexadas a partir del análisis crítico del discurso.

\section{La enseñanza como manifestación de la justicia social hacia los estudiantes}

La educación es un derecho y su acceso está en cuestión, para un sector del pensamiento socioeconómico este debe ser gratuito pero para otro debe ser cobrado. Un sector más moderado considera que el Estado debe garantizar el derecho e involucrar en el pago de un porcentaje al usuario, es decir, la carga debería ser compartida. Sea cual sea la teoría que se pretenda acoger, la educación es un acto de justicia hacia aquellas personas que acceden a un servicio y que manifiestan una necesidad para su desarrollo como seres humanos y la función del docente no debe ser ajena a esta necesidad. Connell (1997) considera que deben existir tres principios orientadores en el diseño curricular para la manifestación de la justicia social: el principio de los intereses de los menos favorecidos, el principio de la participación y la escolarización común y por último el principio de la producción histórica de la igualdad. 
Específicamente en Colombia, como lo sostiene García (2010), la profesión jurídica sufrió cambios importantes a partir de 1960, permitiendo que una mayor cantidad de estudiantes ingresaran a las aulas para formarse como abogados; de manera especial después de la expedición de la Ley 30 de 1992, cuando con fundamento en la autonomía universitaria aumentó la oferta de programas de derecho, elevando la matrícula a niveles no vistos con anterioridad.

Por otra parte, un alto porcentaje de los profesores en derecho no tiene formación en pedagogía, a medida que transcurre el tiempo algunos que permanecen vinculados a las instituciones ven la necesidad de realizar estudios de postgrado en este ámbito, tal vez sea por la necesidad de permanecer en el medio o porque han encontrado en la docencia una vocación que ayuda a encontrar un propósito de vida. Los requisitos mínimos para ser docente en las universidades del sector público en Colombia se limitan a un título de pregrado, un título de postgrado (no se especifica si especialización o maestría) y dos años de experiencia en docencia o dos años de experiencia laboral como profesional (es homologable) ${ }^{2}$. Esto evidencia que la labor docente de los profesores de derecho es empírica porque es basada en la práctica conforme a su experiencia.

El empirismo en la labor docente trae consecuencias de diversa índole. Por ejemplo, el profesional sin formación pedagógica que desea enseñar puede encontrar en esta labor algunas competencias de las que no se haya percatado en su propia vida; esto hará que opte por el camino de la enseñanza y su vinculación será genuina. Por lo tanto, buscará la permanencia, la profesionalización de esta labor y sobre todo establecerá los métodos adecuados para el desarrollo de esta destreza. También existen profesionales que se vinculan porque equivocadamente creen que pueden generar unos ingresos monetarios extras o porque desean ganar

2 Estos requisitos se encuentran regulados en el Artículo 70 de la Ley 30 de 1992 que reza: "para ser nombrado profesor de universidad estatal u oficial se requiere como mínimo poseer título profesional universitario". En el caso de instituciones como la Universidad Militar se requiere título de postgrado y experiencia de dos años conforme al Acuerdo 04 de 2004. experiencia para poder acceder a un cargo en la rama judicial u otro sector del poder público. La motivación errónea hace que los profesionales que se encuentran en el grupo de aquellos que lo hacen por necesidad terminen apartándose del medio, pero detrás de ellos, quedan los estudiantes tropezados sin haber recibido la enseñanza y el ejemplo ético debido.

García y Ceballos (2019) catalogan la docencia universitaria en derecho como una subprofesión jurídica ${ }^{3}$, es decir, derivada de la función de abogado, sin embargo, como se ha evidenciado, el sistema de vinculación en Colombia no es riguroso como sí lo es en otros países. Los autores describen el arduo proceso para ser docente universitario en Alemania, en el cual el aspirante debe pasar por tres etapas: la primera consiste en cursar un doctorado, la segunda consiste en el desarrollo de una investigación para la habilitación ${ }^{4}$ que se deriva de una la calificación sobresaliente obtenida en su tesis doctoral (solo el $2 \%$ terminaron este proceso en 2016); la tercera y última etapa consiste en recibir el título de docentes privados, lo cual los habilitará para regentar una asignatura sin la supervisión. En este caso, la academia es una profesión que debe ser ejercida por una persona que se dedique a esto toda su vida.

En este escrito se pretende describir aspectos de justicia social que deben ser tenidos en cuenta por los docentes de derecho, aunque al momento de su vinculación tuvieran o no formación en educación. En Colombia la profesión docente en derecho se ha ejercido tradicionalmente por personas que no cuentan con formación en pedagogía, como ocurre en México cuyo acceso: "depende en buena medida de la voluntad política de cada universidad" (García y Ceballos, 2019, p.43). Lo ideal es que exista una debida motivación para ejercer la enseñanza del derecho, la cual puede encontrarse a medida que pasa el tiempo y la universidad contribuya con los planes

3 Las subprofesiones jurídicas según los autores García y Ceballos (2019) son aquellas que ejercen los abogados, entre ellas están la docencia, los cargos públicos en la rama judicial (jueces, fiscales), notarios y litigantes.

4 La habilitación se puede obtener también con la publicación de artículos en revistas de investigación avaladas en Alemania. 
de educación formal para aquellos docentes que pretenden seguir en esta labor.

Es necesario entender que la justicia en términos de Rawls (2012) implica apoyar a las personas menos favorecidas a partir de su posición, que en este caso son los estudiantes, es decir, la manifestación del principio de justicia se evidencia cuando el docente se pone en el lugar de la persona que requiere el derecho a la educación.

El primer aspecto lo ha descrito Reyes (2011) quien afirma que no hay justicia sin memoria, porque es esencial que la persona que pretenda dar a conocer una teoría haga memoria de su época de estudiante (memoria de sí mismo) y de la historia de la educación tradicional (memoria del contexto) para encontrar aquellas falencias que pueden subsanarse por medio del ejercicio de la docencia. Los estudiantes ven en el docente el canal o el medio que tienen para encontrar su camino. La memoria en términos de Benjamin (2001) es un medio para construir sobre lo olvidado, porque la historia ha sido escrita por los ganadores y los olvidados han sido los menos favorecidos, aquellos que no han tenido bienes ni educación, por esto, la justicia se construye sobre el recuerdo de la injusticia.

Reconocer el núcleo semántico de la injusticia y hablar desde ahí de la justicia. El secreto del valor teórico de la injusticia lo tiene la memoria, de ahí el lugar estratégico de esta categoría. Sin memoria la injusticia deja de ser actual y, lo que es más grave, deja de ser (Reyes, 2011, p.27).

En los libros siempre aparecen los protagonistas, por ejemplo, no hay rastros de los albañiles que construyeron la gran muralla china, así lo expone Brecht (2017) en su poema Preguntas de un obrero que lee, en derecho se enseña la historia de los vencedores, es decir, la concepción tradicional de la narración de esta. Para Benjamin (2001) no se trata de enseñar la historia e ir en contra de los que la escribieron para volver a un círculo vicioso sin escapatoria, se trata de enseñar un nuevo mesías que busca traer vida frente a la muerte causada por aquellos próceres que han derramado sangre, es decir, para el autor alemán el mundo venidero mira para atrás, se busca redimir a todos los muertos de la historia que han sido derrotados por la injusticia.

Lo primero que debe tener en cuenta el docente en la enseñanza es la garantía de los derechos y la memoria de aquellos que han sido olvidados, es decir, estar conectado con el neocontractualismo y sus nuevas tesis de justicia y consensos. Un docente de derecho debe tener bases iusfilosóficas que le permitan comprender un nuevo derecho con enfoque en los desfavorecidos en la historia, que en este caso son los estudiantes.

El segundo aspecto sugerido para garantizar la justicia social en la enseñanza del derecho moderno lo explica la bioética global, concebida por Van R. Potter en la década del setenta para vincular las ciencias exactas y las humanidades como un puente. Contreras (2017) afirma que en la actualidad innumerables autores ven la necesidad de acoger esta teoría para enfrentar la crisis ecológica-social actual y para vincularla a los procesos de desarrollo sostenible y derechos humanos. La necesidad de vincular la teoría del derecho con las humanidades surge por la crisis de valores que se observa en el ejercicio del derecho, porque: "hay ciencia, entendimiento, conocimiento, pero nos falta aún comprensión, sabiduría, sensatez. Nos hace falta salir de esta Edad de hierro planetaria" (Osorio, 2008, p.110).

La crisis de justicia en la enseñanza del derecho es que esta va ligada al progreso profesional, laboral y económico (sobre todo a este último); para los docentes tradicionales no deben existir límites morales en el ejercicio de la profesión. Las sugerencias en tono de bromas van encaminadas a que los abogados no deben tener sentimientos ni alma y que deben buscar el beneficio para sus clientes sin importar el camino a recorrer o lo que se tenga que hacer; en el ejercicio del derecho existen prohijados que tienen el imaginario que entre más corrupto sea el abogado mejor será su defensa. La crisis de valores en el derecho se complementa con el ejemplo de los abogados mediáticos que se prestan para postular sus ideologías sin infundir análisis crítico, lo mismo hacen los docentes al defender sus tesis neoliberales sin razonar sobre la justicia y el desarrollo sostenible. 
El progreso ${ }^{5}$ tiene sus paradojas. Arent (2003) explicó el contexto del progreso al aducir que en Auschwitz no se moría la gente sino que se fabricaban cadáveres, es decir, lo que para unos fue el genocidio más cruel de la historia de la humanidad, para los nazis era la manifestación del progreso con el fin de purificar la especie humana por medio de una funesta eugenesia. En el derecho se pretende fabricar abogados sin espíritu crítico y apartados de la ética. El progreso a partir de una lógica científica y neoliberal no tiene un contenido humano, se habla de calidad de vida, producción, pero no de humanidad, igual pasa en la enseñanza del derecho. Benjamin (2001) describió el progreso en forma metafórica situándolo como un ángel que caminaba hacia adelante pero con la mirada hacia atrás, lo cual explicaba que el progreso a partir de lo neoliberal va dejando atrás la ruina, es decir, la historia del progreso ha sido la historia de la catástrofe.

Esta catástrofe es descrita por Kennedy (2007) quien basa su crítica en el discurso excesivo de derechos sin transformación social. Para el autor estadounidense los profesores defensores del progreso mercantil no permiten la enseñanza de los principios generales del derecho, la crítica y la adopción de los valores como punto de partida al tomar una decisión en justicia y lo describe así:

parecería que todos estamos atrapados al servicio del statu quo, llevando adelante el proceso de profesionalización. Introducimos a los estudiantes en carreras de Derecho dominadas por el mercado de trabajo y la cultura profesional que están dados, que no cambiarán demasiado sin importar lo que hagamos en las clases. Es una pregunta abierta la que cuestiona acerca de si hacer algo en las aulas implica

5 El progreso siempre ha sido entendido como un fenómeno que indica una mejora en la condición del ser humano. El concepto de progreso ha tenido que ser reinventado en su análisis. La paradoja tratada en el presente artículo tiene relación con la idea contemporánea que indica que el progreso según Rousseau (2006) puede generar hombres materialmente ricos y poderosos pero absurdamente amorales. Este concepto moderno implica que progresar no necesariamente es mejorar, porque los costos de ciertos avances han generado cierta destructividad que hoy se tornan como tema central de un mundo globalizado y biocentrista. Esta visión contradice lo que tradicionalmente se ha entendido por progreso. un adoctrinamiento o una prédica y es, consecuentemente, profesionalmente ilegítimo (p. 87).

\section{Primera discusión}

Los aspectos de justicia social que deben ser tenidos en cuenta por los docentes de derecho deben basarse en el marco de una justicia curricular conforme a Connell (1997) apoyado por los aspectos descritos. Se discute en primer lugar que la justicia en la enseñanza del derecho se manifiesta cuando el docente pueda comprender que el estudiante está en una condición de necesidad, para lo cual, el docente deberá recurrir a la memoria (del pasado de sí mismo y del contexto) como mecanismo de justicia.

En segundo lugar, la memoria histórica hizo que se reconociera que la enseñanza de los valores debe priorizarse sobre la enseñanza de lo teórico y al progreso descrito por Walter Benjamin, por lo tanto, se debe crear un puente entre la bioética global y la ciencia con el fin de humanizar la enseñanza para entender que el progreso capitalista trae consigo ruina. La enseñanza debe generar que los grandes olvidados de la historia como las mujeres y los menos favorecidos se incluyan, porque en nombre del progreso se han cometido las peores barbaries ya que generalmente la enseñanza ha buscado excluir a los que supuestamente no sirven para el ejercicio de una profesión, a los olvidados, a los llamados marginados.

En tercer lugar, la justicia social en las aulas del derecho se puede manifestar cuando existe una seriedad en la moralidad de los docentes, así lo adujo Kennedy (2007) quien afirmó que un docente al ser consciente de que el derecho es política termina convirtiéndose en un predicador, en una persona que inspira a pensar y a tomar una posición respecto de una caso presentado en las aulas con un sentido crítico y objetivo. El papel del docente va mucho más allá del conocimiento que pueda generar por medio de sus clases, el futuro profesional necesita inspiración en varios aspectos como el conocimiento de los presupuestos éticos y filosóficos de su profesión como también es importante que en derecho el docente ejerza el litigio y enseñe con base en estas experiencias. 
No es posible negar el desánimo que puede generar la labor docente, sin embargo, esto no debe ser causal de actuar de manera injusta frente a los estudiantes, por ejemplo, la inasistencia injustificada por la dedicación a objetivos egoístas genera imaginarios de injusticia y de frustración en los educandos que se repiten en el ejercicio de la administración de justicia, por ejemplo, las denuncias por delitos querellables están represadas y cuando el abogado asiste al despacho del fiscal a preguntar por el estado de su proceso, la respuesta es que el fiscal está en vacaciones, o estudiando, o en comisión y su proceso no ha tenido movimiento y pasan los meses y la denuncia termina siendo archivada. Por esta clase de situaciones la justicia entra en crisis y así pasa también con el ejercicio del derecho, abogados que menosprecian al cliente.

La docencia no es ajena a la injusticia. Algunos profesores de carrera administrativa no desean impartir clases, no les interesa, no consideran un acto de justicia retribuir lo que a ellos se les ha dado y se refugian en otros aspectos de la carga académica, lo cual hace que su labor pierda el sentido altruista que el fin de la docencia es la dedicación a la enseñanza.

\section{La ética de la ayuda humanitaria en la labor docente: la población estudiantil y sus capacidades}

En este apartado se pretende describir los criterios básicos de una ética en la labor docente como una ayuda humanitaria para la población estudiantil de escasos recursos. En este sentido, no se puede pasar por alto que la desigualdad no es exclusiva de la clase social o la estratificación, sino que también es consecuencia de otras dimensiones sociales que la complejizan como la etnia o el género. Florián (2019) reconoce que en factores de desigualdad, la pobreza juega un papel sustancial y ha tenido que ser diferenciada y estudiada. Pueden distinguirse, por lo tanto, la pobreza absoluta, la pobreza social y la pobreza multidimensional. Así mismo, se hace necesario reconocer que existen diferencias entre marginación y exclusión, pues la primera se presenta hacia los grupos desamparados a fin de alejarlos de las dinámicas de la sociedad, mientras que la exclusión viene a ser la consecuencia, es el rechazo hacia quienes han sido marginados por considerarlos de menor categoría 6 .

Es necesario lograr conexión emocional con los estudiantes y ayudar a encontrar las capacidades necesarias para convertir los derechos en libertades reales. Los docentes se enfrentan a estudiantes que han sido marginados y excluidos por la sociedad y lo ideal es que los docentes no se conviertan en un medio que aumente esta desigualdad palpable. Sen (1996) considera que una nación se mide por las capacidades que tienen los ciudadanos para ejercer libremente sus derechos, es decir, lo indispensable es que cada habitante pueda tener la capacidad de acceder a un servicio, que en el caso propuesto es la educación. Las capacidades de los ciudadanos no se ejercen por los fenómenos de marginación y marginalidad, la primera como el acto de exclusión que ejercen las llamadas castas hacia los pobres y la segunda como la condición en la que se encuentran aquellas personas que no tienen acceso a los derechos, por esto es necesario realizar una somera identificación de la población estudiantil.

La población cuyo estrato socioeconómico es del 1, 2 y 3 es hacia la que van dirigidas las políticas públicas de ayuda estatal de acceso a la educación. No es objetivo de este artículo verificar la efectividad de estas políticas sino establecer que esta colectividad es la menos favorecida en capacidades para el ejercicio de sus derechos con relación al estudio del derecho. Para 2017, de los 165 programas de pregrado en derecho que hay en Colombia, 33 contaban con la Acreditación en Alta Calidad, el restante (132) tenían el Registro Calificado que es la licencia que otorga el Ministerio de Educación a las facultades que cumplan unos mínimos de requisitos. Según Legis (2016) de casi 139.000 estudiantes, más de 99.000 están matriculados en las facultades que tienen el registro calificado, es decir, el $72 \%$ de la población.

6 Para Florián (2019) los fenómenos de marginación, marginalidad y exclusión se unen y actúan dinámicamente para crear un sentimiento subjetivo en las personas que discriminan y generan fobia hacia los menos favorecidos y su consecuencia es la injusticia. Los estudiantes de bajos recursos deben enfrentarse a estas situaciones que desde las aulas las reproducen en el ejercicio profesional. 
La lectura de estas cifras podría dar como interpretación que más de las dos terceras partes $(2 / 3)$ de la población estudiantil de las facultades de derecho no están matriculados en universidades acreditadas en alta calidad que albergan estudiantes de estratos 1, 2 y 3. Esta población no es mayoría en estas instituciones, razón por la cual, se puede deducir que el $72 \%$ de la totalidad de los estudiantes de derecho lo hacen en universidades dirigidas a personas de clase media, media baja y baja, con precios relativamente accesibles para que estas personas puedan mejorar su calidad de vida.

García y Ceballos (2019) afirman que no solo existen demasiadas facultades de derecho, sino que existe una disparidad en lo referente a la calidad en los centros educativos. Según sus hallazgos el $71 \%$ de los nuevos abogados egresan de facultades de baja calidad y bajo costo. Esto genera que las universidades que cuentan con Acreditación de Alta Calidad tengan, en buena medida, una buena oferta en lo referido a posgrados, porque los egresados de las universidades de baja calidad compensan las carencias y esto se da por el contraste existente en los pregrados.

El objetivo de cualquier ministerio de educación de un país es lograr que todas sus instituciones cumplan con los estándares de alta calidad para que los egresados puedan competir en igualdad de condiciones y oportunidades. La realidad es otra, los egresados de las universidades que cuentan únicamente con el registro están en inferioridad con relación a las acreditadas en alta calidad, por ejemplo, según el Instituto Colombiano para la Evaluación de la Educación Superior (ICFES) en el año 2016 en las pruebas Saber-Pro las cifras indicaron que un estudiante de una facultad no acreditada obtuvo en promedio un rendimiento del $8.27 \%$ menor que el estudiante de una facultad acreditada en aspectos de lectura crítica, inglés y razonamiento cuantitativo.

Los egresados de las facultades que solo gozan del Registro Calificado y no de la Acreditación en Alta Calidad tienen serias dificultades para el acceso a firmas o bufetes reconocidos, así como a los cargos de poder. Por ejemplo, en la actual presidencia de la República de Colombia, el presidente, la vicepresidenta y 6 ministros del gabinete son abogados egresados de universidades altamente acreditadas (Presidencia de la República, 2018), cuyo acceso se torna casi imposible para personas de escasos recursos.

Lo anterior evidencia que existen estudiantes de derecho de escasos recursos en universidades privadas que no cumplen los estándares en alta calidad, por lo tanto, sus capacidades se limitan por su origen y por sus condiciones, no vienen de colegios bilingües, la gran mayoría no ha salido del país, cuentan con un trabajo extra para pagar sus estudios y mantenerse a ellos mismos y/o a su familia, el acceso al transporte y su costo se torna complicado, son hijos de campesinos radicados en ciudades capitales por la pobreza o la violencia, por lo que en sus casas no hay biblioteca o salas de estudio. La esperanza de salir de la marginalidad se funda en la educación, sin embargo, las probabilidades para que el sector estudiantil de escasos recursos compita en igualdad de oportunidades y capacidades se reduce al establecer políticas económicas que abren la brecha entre ricos y pobres.

Esta desigualdad también se manifiesta una vez se adquiere el título universitario en una institución de baja calidad. García y Ceballos (2019) afirman que los cargos con baja retribución están acaparados por egresados de universidades catalogadas de baja calidad. Esto ocasiona una estratificación en los abogados y que los criterios de calidad sean medidos por factores de posibilidad de empleabilidad, lo cual ocasiona cierto apartheid educativo, que varios autores, entre ellos Felouzis, Liot y Perroton (2005) quienes consideran que la segregación étnica y urbana juegan un papel significativo en las desigualdades que se viven en la educación.

Anteriormente se había indicado que las nociones de marginación y exclusión interactuan para crear mayor pobreza. Florián (2019) indica que existe la marginalidad y se trata de un fenómeno en el cual un grupo de personas son enviadas directa o indirectamente en un sector geográfico o estratificado retardando la llegada de la modernidad y obstaculizando el proceso de desarrollo económico y social. La marginalidad es derivada de la marginación, por lo tanto, en el campo universitario se presenta esta dinámica: los estudiantes 
marginados se matriculan en universidades que se encuentran en cierto nivel de marginalidad, al salir, los egresados serán excluidos y rechazados por una sociedad que tiene preparados los mejores cargos a los juristas de universidades acreditadas en alta calidad. A este círculo se le debe sumar otra preocupación, que no hay docentes con los valores altruistas y la ética requerida.

En este ámbito, juegan un papel las limitaciones presupuestales de la educación superior determinadas por los gobiernos, que al lado de "salvajes aumentos" de las matrículas universitarias reducen la visión de la juventud como futuro político, cayendo en la tarea simple de ejercitar a los jóvenes para que se conviertan en consumidores (Bauman, 2013). Superar tal brecha de desigualdad implicaría asumir compromisos estatales serios, vía políticas públicas que enfrenten los enfoques de mínima regulación y ampliación del espacio al juego del mercado.

Es así como los docentes juegan un papel importante en la reducción de la desigualdad social y en la garantía de acceso a los derechos para aquellos que por circunstancias no han podido desarrollar sus capacidades. La mayoría de los estudiantes de escasos recursos consideran que lo importante es aprender un área disciplinar y pagan para que un docente les enseñe estrictamente el contenido programático; el docente presionado por su evaluación y su continuidad laboral cae en la trampa y lo que hace es disminuir la expectativa en el estudiante haciendo de él un ser conformista, así lo describe Córdoba (2006):

en el ámbito de las desigualdades socio-culturales el enfoque de las capacidades permite advertir dos obstáculos para compatibilizar la atención a la diversidad y la calidad educativa: uno es la influencia de la subcultura de la pobreza en la conversión de los currículos y demás recursos pedagógicos en capacidades educativas, y otro es la influencia que en la misma cuestión tiene el hecho de que tales recursos sean bienes posicionales (p. 376).

La promoción de las capacidades está a cargo del docente quien al politizar el derecho establecerá un vínculo emocional con los estudiantes a fin de comprender las circunstancias de su alumnado. Etxeberria (2008) da una lista de sentimientos que son relevantes para el impacto en lo público y propone la enseñanza de estos en la ciudadanía a fin de proyectar las dos capacidades más importantes que otorgan las emociones para el desarrollo de los derechos: la motivacional y la relacional. En las dos opera un sentimiento que debe manifestarse en el ejercicio de la docencia en procura de una ética para que esta labor sea más humana: la compasión.

Etxeberria (2004) también considera que el autointerés inteligente, la justicia, la solidaridad y la compasión son los fundamentos éticos de la ayuda humanitaria, por lo tanto, si la docencia es una labor que implica conexión con estudiantes y estos se encuentran en condiciones difíciles tal como las descritas anteriormente, debe catalogarse como una ayuda a quienes han sido menos favorecidos. En el numeral anterior se estableció que la justicia social en las aulas del derecho se manifiesta cuando existe una seriedad en la moralidad de los docentes, se politiza el derecho y se establece un puente entre lo teórico y lo humano para que el progreso tropiece a las futuras generaciones. En este numeral se propone establecer que los criterios básicos para el ejercicio de la docencia del derecho son el enfoque en las capacidades de los menos favorecidos (el cual ya se trató) y la compasión como un sentimiento y un fundamento ético.

La compasión suele confundirse con la lástima. Según la Real Academia Española (Rae) la compasión viene del latín cumpassio y del griego $\sigma v \mu \pi \alpha \dot{\theta} \theta \varepsilon \iota \alpha$ (sympathia) que significa "sufrir juntos" y hace referencia al sentimiento de empatía hacia al otro, es decir, afectarse por el sufrimiento del otro y estar presto a cualquier necesidad. La lástima hace referencia a la posición social de superioridad con sentimiento de dolor frente a la necesidad del otro, la diferencia entre los dos conceptos radica en que la compasión implica la existencia de la compañía frente al dolor del que lo padece, mientras que en la lástima el sentimiento de dolor por el otro se vive a la distancia, en la compasión hay altruismo, en la lástima no.

La compasión permite la compenetración del docente en las esferas sociales y económicas del 
estudiante para que exista un discernimiento frente a la realidad que vive. Se había indicado anteriormente que el efecto de la justicia social en el aula se manifiesta cuando el docente se pone en los zapatos del estudiante y la compasión es el sentimiento que logra la efectividad de este propósito. La teoría de las capacidades de Sen (2002) permite que la educación se enfoque en el desarrollo social y económico del estudiante, es decir, nivelarlo en oportunidades para la promoción de las libertades, por encima del desarrollo económico, porque en últimas la felicidad viene a convertirse en un fin individual y común en un sentido aristotélico.

La ética de la ayuda humanitaria en la labor docente se manifiesta cuando existe un enfoque de las capacidades para la promoción de las libertades, esta visión "permite comprender la relación entre educación y libertad en contextos sociales con desigualdades económicas, culturales y de género" (Córdoba, 2006, p. 377), también permite una evaluación acerca de la calidad educativa referida a lo que le pueda aportar al estudiante en el desarrollo de sus metas y sus propósitos profesionales con el fin de salir del estado de marginalidad en el que se encuentra.

\section{Bioética y la función docente}

Un aporte trascendental para establecer la importancia del sentimiento de compasión en la labor profesional docente se encuentra desarrollado por la bioética en el concepto de Dignidad y los Derechos Humanos establecidos en la Declaración Universal sobre Bioética y Derechos Humanos de la Unesco (2005), que en sus objetivos busca promover el respeto por la dignidad humana protegiendo los derechos humanos y las libertades humanas y que reza: "se habrán de respetar plenamente la dignidad humana, los derechos humanos y las libertades fundamentales" (art. 3). Miralles (2016) considera que la biojurídica permite que el ejercicio del derecho se mantenga con unos principios éticos-jurídicos que permiten el desarrollo de cualquier actividad, por esta razón, cuando existe relación con el otro debe partirse del presupuesto de su humanidad y su respeto.
La bioética en sus inicios fue acogida por la ciencia médica, razón por la cual, los principios y los fundamentos eran considerados eminentemente de contenido clínico. La extensión de esta ciencia se da por el enfoque biocentrista del conocimiento y en este sentido el campo de la educación no ha sido ajeno a este ámbito. La bioética de contenido clínico ha desarrollado estudios acerca de la relación médico-paciente. Rodríguez Silva (2006) presenta una revisión de los distintos aspectos de las relaciones interpersonales entre el profesional de la salud y el paciente junto con sus familiares y concluye que el principal problema en esta relación es uno de los que se han mencionado en este artículo, el sistema capitalista extremo, descrito así:

la política neoliberal imperante en muchos países en que el estado reduce la salud pública, entregándola a consorcios privados que introducen la comercialización en la atención médica. Esta situación ha convertido al paciente en un "comprador", en un cliente con exigencias, y a los médicos en verdaderos "vendedores" (p. 4).

Igual ocurre con la mercantilización de la oferta de la enseñanza del derecho, la cual no permite establecer relaciones de empatía que hacen que el estudiante sea visto como un objeto y no como un ser humano. No puede olvidarse que en Colombia, mientras que después de la segunda mitad del siglo XX disminuyó de manera sustancial la participación de las instituciones de origen oficial que ofrecen la carrera, en una sola década egresaron un número de abogados tan significativo que representa el 58\% del total de abogados que egresaron en la tres décadas anteriores (García, 2010).

La bioética, además de ser un puente entre lo científico y lo humano, se ha preocupado por unir los lazos en las relaciones humanas en todos los campos con el fin de humanizar las profesiones; comenzó con la medicina y su profundización le ha permitido extenderse a las demás disciplinas. Por lo tanto, la transdisciplinariedad permite que los criterios médicos establecidos por la bioética clínica en torno a la relación médico-paciente se puedan aplicar analógicamente en la relación docente-estudiante para el desarrollo del 
futuro profesional conforme a los criterios de Laín Entralgo (1964):

1) Saber ponerse en el lugar del otro.

2) Sentir como él o ella.

3) Disponerse a ayudarle cuando enfrenta dificultades

Estos parámetros han sido desarrollados con el fin de establecer las características de la ética del ejercicio de la medicina y pueden ser extendidos a la función del docente en el ejercicio de la compasión.

\section{Segunda discusión}

Es complejo discernir la compasión en términos prácticos: "hoy, sin embargo, la fundamentación del humanitarismo en la compasión está bajo sospecha" (Etxeberria, 2004, p. 58). Esta crítica realizada por el filósofo español se hizo porque considera que la compasión debe ser un fundamento de la motivación y la justificación ética de la ayuda humanitaria y dejar de ser un mero sentimiento. La compasión hacia el estudiante por parte del docente debe estar ligada no solamente al aspecto de la justicia sino a la dignidad del estudiante. Lévinas (1991) entendió la compasión como un estado de responsabilidad compleja hacia el otro, ahora bien, el docente se expone al otro, porque el otro es al que se responde y por el que se responde. El docente está en una situación que debe ser expuesta para su crecimiento, por lo tanto, compasión, justicia y dignidad como principios éticos hacia los estudiantes deben complementarse.

La compasión que dignifica al estudiante implica que el docente debe estar presto a la atención personal en la formación y la búsqueda de las capacidades por medio de la enseñanza y la formación de los valores. El docente debe contextualizar el origen y el medio socioeconómico del estudiante para que por medio de su vocación pueda complementar las falencias. La compasión hace que el estudiante se vincule emocionalmente con el docente, le permite soñar, ejercer un espíritu crítico y comprender que lo mejor para su formación profesional es la exigencia combinada con la humanidad. El error común de los docentes de derecho es la indiferencia por la condición del estudiante, existe el menosprecio hacia el estudiante pobre, hacia el que tiene falencias en su aprendizaje o se llega al otro extremo: se disfrazan con falsa humildad y sentimiento de lástima al otorgar calificaciones sin observar esfuerzo y mérito para obtener buenas evaluaciones de los estudiantes y así mantenerse en el medio laboral.

La transdisciplinariedad de la bioética permite la aplicación analógica de la relación médico-paciente para establecer la interacción del docente-estudiante de derecho y permite que el docente comprenda que el estudiante no deba ser tratado como un cliente, sino como un ser humano titular de derechos que necesita ejercer sus libertades conforme a las capacidades que el docente le ayude a ejercer. Además, el futuro profesional del derecho podrá reproducir estas relaciones al entablar una defensa en la que comprenderá a su prohijado a partir de lo enseñado por sus profesores.

\section{Conclusión}

Es relevante constituir criterios que permitan complementar la labor de la enseñanza tradicional del derecho para constituir una ética en la garantía de la justicia social para los estudiantes menos favorecidos, la búsqueda de sus capacidades y el vínculo emocional docente-estudiante. Esta labor no es fácil, pues implica la comprensión por parte del docente de estos factores: su función, la necesidad de fortalecer su profesionalización, el contexto socio económico al cuál se dirige y la necesidad de la formación en valores éticos y democráticos. Aunque el Estado es el directo responsable de la crisis de la educación jurídica en Colombia, el docente universitario es parte de una primera solución al trabajar a pesar de las falencias estatales.

El artículo evidencia de manera breve la disparidad existente en la educación jurídica ofrecida en las instituciones de educación superior que genera una estratificación en la función de los abogados, razón por la cual, la responsabilidad no solo está en cabeza del estado sino en las universidades que se amparan en el principio de autonomía universitaria para evitar el control que debería existir para evitar la desigualdad que se presenta en la 
educación y en el ejercicio de la profesión. No es posible deducir si la estratificación influye en la ética o no de sus egresados, pero si se puede afirmar que las consecuencias económicas y sociales se miden por los factores de desigualdad. El primer paso para solventar esta especie de injusticia está en la labor del docente, el segundo paso, lo tendrá que dar el Estado.

Se pretende que el docente involucrado en la enseñanza del derecho lo haga con la debida motivación que la vocación exige, independientemente si tuvo o no formación pedagógica. La exigencia radica en la necesidad de constituir bases iusfilosóficas de justicia con memoria basadas en el neocontractualismo y la bioética global para vincular la dogmática del derecho con las humanidades. Se estableció en este artículo la importancia de entender que el derecho es política y así debe enseñarse, contexto en el cual el estudiante no debe considerarse como un cliente sino como una persona sujeta de derechos (a diferencia del modelo neoliberal).

En un aspecto general se encontró que la mayoría de la población estudiantil de las facultades de derecho no cuentan con las capacidades necesarias para ejercer libremente sus derechos por situaciones de marginación y marginalidad, por lo tanto, el docente al reconocer estas falencias debe vincularse emocionalmente con sus educandos así como lo hace el médico con su paciente para lograr reducir aquellas desigualdades socioeconómicas. El papel del docente debe ser inspirador en ética, multidisciplinariedad y dejar atrás los modelos tradicionales de enseñanza para que el estudiante de derecho observe un modelo de abogado más eficiente que aquel que presentan los medios de comunicación, los cuales muestran a los abogados impetuosos, doble moralistas, altivos, arrogantes, insolentes, altaneros, avaros, indiferentes con sus clientes, irrespetuosos, totalitaristas e ideólogos en corrientes políticas extremas.

\section{Referencias}

Arent, H. (2003). Eichmann en Jerusalén. Un estudio sobre la banalidad del mal. Barcelona, España: Lumen.

Bauman, Z. (2013). Sobre la educación en un mundo líquido. Bogotá, Colombia: Editorial planeta.
Benjamin, W. (2001). Tesis de filosofía de la historia. Barcelona, España: Etcétera.

Brecht, B. (2017). Preguntas de un obrero que lee. Recuperado de: https://www.taringa.net/+apuntes_y_monografias/preguntas-de-un-obrero-que-lee-poema_vee9m

Congreso de la República de Colombia (1992). Ley $30 \mathrm{del}$ 28 de diciembre de 1992 por la cual se organiza el servicio público de la Educación Superior. Bogotá D.C.: Congreso de la República de Colombia.

Connell, R.W. (1997). Escuelas y justicia social. Madrid, España: Ediciones Morata.

Contreras, D. (2017). Sobre la urgencia de una bioética global. Revista Digital Universitaria (RDU), 18(8). Doi: http://doi.org/10.22201/codeic.16076079e.2017.v18n8. a1

Córdoba, R. C. (2006). Desarrollo humano y capacidades. Aplicaciones de la teoría de las capacidades de Amartya Sen a la educación. Revista española de pedagogía, 64(234), 365-380.

Etxeberria, X. (2004). Ética de la ayuda humanitaria. Bilbao, España: Desclée de Brouwer.

Etxeberria, X. (2008). Por una ética de los sentimientos en el ámbito público. Bilbao, España: Bakeaz.

Felouzis, G., Liot, F. y Perroton, J. (2005). L'apartheid scolaire. Enquete sur la ségrégation ethnique dans les collèges. París, Francia: Seuil.

Florián, E. S. T. (2019). Bioética y biopolítica: la discriminación a los habitantes de la calle drogodependientes por su pobreza. Principia Iuris, 16(33), 31-60.

García V. M. (Ed.). (2010). Los abogados en Colombia. Bogotá, Colombia: Universidad Nacional de Colombia, Facultad de derecho, ciencias políticas y sociales.

García, M., y Ceballos, M. (2019). La profesión jurídica en Colombia. Falta de reglas y exceso de mercado. Bogotá, Colombia: Dejusticia.

Kennedy, D. (1992). Nota sobre la historia de CLS en los Estados Unidos. Revista Doxa, Universidad de Alicante. doi: https://doi.org/10.14198/DOXA1992.11.12

Kennedy, D. (2007). Politizar el aula. Academia: revista sobre enseñanza del derecho de Buenos Aires, 5(10), 85-94.

Laín Entralgo, P. (1964). La relación médico-enfermo: historia y teoría. Madrid, España: Revista de Occidente. Recuperado de http://www.cervantesvirtual.com/ obra/la-relacion-medico-enfermo-historia-y-teoria/

Lévinas, E. (1991). Ética e infinito. Madrid, España: Visor. Instituto Colombiano para la Evaluación de la Educación [ICFES] (2018). Saber Pro. Informe Nacional de resultados 2016-2017. ICFES, Ministerio de Educación Nacional. Recuperado de https://www.icfes.gov.co/ 
documents/20143/238004/informe $\% 20$ nacional $\% 20$ de\%20resultados\%20saber\%20pro\%202016\%202017. pdf

Legis (2016). En Colombia, tres de cada 10 abogados se forman en programas académicos con acreditación de alta calidad. LEGIS, Información y soluciones. Recuperado de http://www.legisaldia.com/BancoMedios/ Archivos/comunicadoanunciapropuestareglamentariaparaelevarestandareseducativosprogramasderecho-16\%20.pdf

Miralles, A. A. (2016). Dignidad humana y nuevos derechos. En Santos, J., et al. (Eds.), Bioética y nuevos derechos (pp. 47-78). Granada España: Comares.

Organización de las Naciones Unidas para la Educación, la Ciencia y la Cultura [Unesco]. (2005). Declaración Universal sobre Bioética y Derechos Humanos. Unesco. Recuperado de http://portal.unesco.org/ es/ev.php-URL_ID=31058\&URL_DO=DO_TOPIC\&URL_SECTION=201.html
Osorio, S. N. (2008). Bioética Global y pensamiento complejo. Hacia una emergente manera de ser. Revista Latinoamericana de Bioética, 8(2), 106-113.

Rawls, J. (2012). Teoría de la justicia. Ciudad de México, México: Fondo de cultura económica.

Reyes, M. (2011) Tratado de la injusticia. Barcelona, España: Anthropos.

Rodríguez Silva, H. (2006). La relación médico-paciente. Revista Cubana de Salud Pública, 32(4), 2-9.

Rouseau, J. J. (2006). Discurso sobre las ciencias y las artes. Biblioteca virtual universal. Recuperado de https:// www.biblioteca.org.ar/libros/131655.pdf

Presidencia de la República. (2018). Iván Duque Márquez. Presidente de la República (2018-2022). Presidencia de la República. Recuperado de https://id.presidencia.gov. co/gobierno/presidente-ivan-duque

Sen, A. (1996). Capacidad y bienestar. En Sen, A., y Nussbaum, M. (Eds.), La calidad de vida, (pp. 54-83). México D.F., México: Fondo de Cultura Económica.

Sen, A. (2002). Rationality and Freedom. Cambridge, United States: Mass Belknap. 
